\title{
ESTRATÉGIAS EDITORIAIS E TERRITORIALIZAÇÃO DO CAMPO PEDAGÓGICO: UM LIVRO DE SAMPAIO DÓRIA SOB A PENA DO EDITOR DA BIBLIOTECA DE EDUCAÇÃO
}

\author{
Marta Maria Chagas de Carvalho \\ Universidade de São Paulo, Brasil.
}

Resumo

Este artigo analisa a inserção do livro Educação moral e educação econômica, de autoria de Sampaio Dória, na coleção Biblioteca de Educação, organizada por Lourenço Filho para a Companhia Melhoramentos de São Paulo. O texto analisa a territorialização promovida pelos dispositivos textuais e editoriais de repartição e apresentação dos volumes da coleção. Sustenta que, ao enquadrarem Dória como pedagogista social, esses dispositivos situam-no no que o editor entendia como periferia do programa de renovação da escola brasileira que a Coleção promovia. Mostra como os temas que Lourenço Filho considerava nucleares no movimento internacional pela Escola Nova foram atribuídos a outros autores, apesar de sua recorrência na produção de Sampaio Dória.

Palavras-chave: Lourenço Filho, Pedagogia da Escola Nova, coleções, estratégias editoriais.

\section{EDITORIAL STRATEGIES AND TERRITORIALIZATION OF PEDAGOGICAL FIELD: A BOOK BY SAMPAIO DÓRIA UNDER THE PEN OF THE EDITOR OF BIBLIOTECA DE EDUCAÇÃO}

\begin{abstract}
The essay analyses the inclusion of Sampaio Dória's book Educação moral e educação econômica in the collection Biblioteca de Educação organized by Lourenço Filho for Companhia Melhoramentos de São Paulo. The text analyses the territorialisation promoted by textual and editorial devices of division and presentation of the volumes of the collection. It assumes that, on account of their classification of Dória as a social pedagogue, they locate him in a situation defined as periphery of the program of renovation of Brazilian school promoted by the collection. It shows the ways the themes that Lourenço Filho judged central in the international movement for the new school were attributed to other authors in spite of their occurrence in Dória's production.
\end{abstract}

Key-words: Lourenço Filho, pedagogy of new school, collections, editorial strategies 


\section{ESTRATEGIAS EDITORIALES Y TERRITORIALIZACIÓN DEL CAMPO PEDAGÓGICO: UN LIBRO DE SAMPAIO DÓRIA BAJO LA PLUMA DEL EDITOR D E LA BIBLIOTECA DE EDUCACIÓN}

Resumen

El ensayo hace el análisis de la inserción del libro Educação moral e educação econômica, escrito por Samapio Dória, en la colección Bilbioteca de Educação, organizada por Lourenço Filho para la editora Companhia Melhoramentos de São Paulo. El texto hace el análisis de la territorialización promovida por los dispositivos textuales y editoriales de partición y presentación de los volúmenes de la colección. Defiende que, por clasificar a Dória como pedagogo social, eses dispositivos lo sitúan en una posición entendida como periferia del programa de renovación de la escuela brasilera que la Colección promovía. Demuestra como los temas que Lourenço Filho juzgaba nucleares en el movimiento internacional por la escuela nueva fueron atribuidos a otros autores, a pesar de su recurrencia en la producción de Sampaio Dória.

Palabras-clave: Lourenço Filho, pedagogía de la escuela nueva, colecciones, estrategias editoriales.

\section{STRATÉGIES ÉDITORIALES ET TERRITORIALISATION DU CHAMP PÉDAGOGIQUE: UN LIVRE DE SAMPAIO DÓRIA SOUS LA PLUME DU ÉDITEUR DE LA BIBLIOTECA DE EDUCAÇÃO}

Résume

Le texte fait l'analyse de l'inclusion du livre Educação moral e educação econômica, écrit par Sampaio Dória,dans la collection Biblioteca de Educação organisée par Lourenço Filho pour la maison d'édition Companhia Melhoramentos de São Paulo. Le texte analyse la territorialisation promue par les dispositifs textuels et éditoriaux de division et présentation des volumes de la collection. Il défend que, à cause de leur classification de Dória en tant que pédagogue social, ils le situent dans une position définie comme la périphérie du programme de rénovation de l'école brésilienne promue par la collection. II démontre comment les thèmes jugés nucléaires par Lourenço Filho dans le mouvement international pour l'école nouvelle ont été attribués à d'autres auteurs en dépit de leur occurrence dans la production de Sampaio Dória.

Mots-clé: Lourenço Filho, pédagogie de l'école nouvelle, collections, stratégies éditoriales. 
E ste artigo analisa a inserção do livro Educação moral e educação econômica, suas bases, sua aplicação nas escolas, de autoria de Sampaio Dória, na coleção Biblioteca de Educação, organizada por Lourenço Filho para a Companhia Melhoramentos de São Paulo. Toma como referenciais de análise as proposições metodológicas de Roger Chartier (1994, 1996, 1997), que ressaltam a importância de considerar a materialidade do impresso e analisar os seus dispositivos textuais e editoriais de modelização da leitura. Explora analiticamente proposições de Olivero (1999) acerca do aparelho crítico que produz a identidade editorial de uma coleção.

A Biblioteca de Educação foi publicada entre 1927 e 1970, lançando 37 títulos com diversas reedições. ${ }^{1} \mathrm{~A}$ análise da configuração material dos volumes publicados permite distinguir uma primeira fase da coleção, que abrange os livros publicados entre 1927 e 1940, fase essa nitidamente diferenciada daquela que, sob o mesmo nome e a organização do mesmo Lourenço Filho, será publicada entre 1940 e $1970 .^{2}$

Dispositivos editoriais e textuais de homogeneização dos volumes produziram a identidade da primeira fase da Coleção ${ }^{3}$, que publicou obras de autores brasileiros e traduções de obras estrangeiras. Entre os dispositivos editoriais de homogeneização material dos volumes destaca-se o padrão uniforme das capas, contracapas, páginas de rosto e páginas de espelho. Os volumes foram editados em brochuras de formato pequeno, que traziam nas capas, em um mesmo padrão de disposição, o nome do autor, o título da obra e o nome da editora.

Além da uniformidade da disposição material das informações exibidas nas capas e contracapas, a página de rosto de cada volume repunha as informações referentes à Biblioteca: seu título, nome do organizador e número do volume que o título recebe ao ser editado pela Coleção, nome da obra publicada; nome do autor e informação sobre seu lugar de inserção profissional, nome do tradutor (quando era o caso) e de sua vinculação

\footnotetext{
${ }^{1}$ Para mais informações acerca da Biblioteca da Educação ver Monarcha (1997), Carvalho e Toledo (2003; 2006).

${ }^{2}$ Observando-se os títulos e autores publicados e lendo-se os textos explicativos do perfil da coleção inscritos nos volumes publicados entre 1942 e 1979, percebe-se que o projeto organizado nos anos 1920 e 1930 é praticamente abandonado: desaparecem dos versos das capas as referências aos títulos anteriormente publicados; poucos passam a ser os livros do período anterior reeditados; os textos de apresentação da coleção desaparecem das contra-capas; a numeração que cada volume recebia ao sair na Biblioteca é abandonada. Assim, a partir de 1942, não restam sequer vestígios do conjunto de obras editadas no período anterior. Além disso, dos 29 títulos publicados nos anos 1920 e 1930, apenas cinco são reeditados nos anos 1940 (os três títulos de Lourenço Filho; Pierón; Moura); apenas cinco nos anos 50 (Dewey, Kilpatrick, Durkheim, Lourenço Filho - Introdução e Testes ABC); e os mesmos 5 nos anos 1960. Há, portanto, um abandono significativo do conjunto de obras que conferiu um perfil à Coleção nas primeiras décadas de sua existência. Assim, apesar da manutenção do nome da coleção e da permanência de Lourenço Filho como seu organizador, o conjunto de obras publicados a partir dos anos 1940 conforma um novo produto editorial, que pouco tem a ver com o projeto inicial. Essa tese é confirmada também pelas mudanças de formato, de capa e de títulos que, indiciando redefinições dos critérios ordenadores do perfil da coleção, conferem a ela, a partir dos anos 1940, uma nova identidade. Assim, levando-se em conta essas diferenças de perfil editorial, pode-se sustentar que o nome de Biblioteca de Educação designa, pelo menos, duas coleções distintas, sob o nome de Lourenço Filho: a coleção publicada nos anos 1920 e 1930 e aquela editada no período 1940-1970. Ver Carvalho e Toledo (2003; 2006).

3 Sobre a coleção como gênero editorial que encarna um projeto de intervenção junto a um público determinado ver Olivero (1999). Sobre a coleção como gênero editorial produzida por dispositivos materiais de modelização da leitura ver Olivero (1999), Toledo (2001), Carvalho e Toledo (2007).
} 
institucional, símbolo e nome da editora. Um retrato do autor é publicado na página seguinte à página de rosto, introduzindo o volume. Entre os dispositivos editoriais e textuais de produção da identidade da coleção destacam-se, especialmente, as informações sobre o perfil da coleção, que aparecem em pequenos textos de apresentação e caracterização da iniciativa editorial nas contracapas e páginas de espelho.

A configuração do espaço gráfico da contracapa dos volumes é dispositivo eficaz de fixação do perfil da Coleção. Nela são reunidas todas as informações sobre o conjunto dos títulos que compõem a Biblioteca, como a relação dos volumes já publicados com o seu preço de venda, os endereços de contato da editora e a relação dos títulos no prelo. É nesse mesmo espaço gráfico que se dispõe uma pequena apresentação do perfil da Coleção e de seu destinatário:

A "Bibliotheca de Educação" torna-se hoje indispensável aos srs professores, normalistas e aos srs pais em geral, diretamente interessados em conhecer as bases cientificas da educação e seus processos racionais. Cada volume conterá sempre um assunto completo, e a coleção toda se distinguirá por duas séries, uma das bases cientificas do ensino, outra de aplicações praticas e critica de sistemas. (Dória, 1928, v. 3, contracapa)

Extraída da contracapa da primeira edição de Educação moral e educação econômica. Suas bases e sua aplicação nas escolas, essa apresentação do perfil da Coleção é a mesma que consta nas contracapas dos volumes anteriormente publicados e nas primeiras edições dos volumes subseqüentes, publicados entre 1927 e 1940. Em todos esses volumes, essa mesma apresentação é reproduzida e amplificada nas páginas de espelho. Nela, a destinação da Coleção é especificada e a escolha do título do volume é justificada pela rarefação de publicações similares no mercado editorial. Assim, na página de espelho de cada volume, pode-se ler:

Dada a deficiência, (para não dizer já a ausência) de livros com esse escopo, em lingua nacional, achamos que a iniciativa vem ao encontro de uma de nossas necessidades de divulgação cultural, devendo encontrar, por isso, boa acolhida dos estudiosos. A "BIBLIOTECA DE EDUCAÇÃO", cuja organização está entregue a um especialista bastante conhecido, será composta, assim, de escolhidas traduções e de originais de autores brasileiros, procurando desenvolver um plano harmônico, no seu conjunto, e, tanto quanto possível perfeito, resumindo os mais salientes problemas educativos da atualidade. Cada volume conterá sempre um assunto completo, e a coleção toda se distribuirá por duas series. Na primeira, de caráter geral, serão expostas as bases cientificas do ensino, já do ponto de vista genetico-funcional da sua organização, já do ponto de vista da finalidade social e moral a que deve tender, para a elevação do homem, como cidadão e como homem. Na Segunda, serão examinados os meios práticos de educação e ensino, tratando-se de modo particular das aplicações que mais nos convenham, com indicações e criticas de sistema Em resumo, a 'BIBLIOTECA DA EDUCAÇÃO' se destina a preencher uma necessidade de ha muito sentida pelos professores brasileiros, sendo de esperar que ela desperte também, pela agitação das boas idéias sobre o assunto, tornadas assim mais acessíveis ao grande público, uma literatura 
nossa de pequenos estudos de iniciação cultural, cujo valor não será preciso encarecer. (Dória, 1928, v. 3, p. 2)

Educação moral e educação econômica. Suas bases e sua aplicação nas escolas é o terceiro volume da Biblioteca da Educação. De autoria de Sampaio Dória, o livro é integrado à coleção por dispositivos editoriais e textuais de modelização da leitura e de produção da identidade da coleção como os acima referidos. Entre esses dispositivos, destacam-se os prefácios, notas de rodapé e o sistema de remissão dos assuntos tratados a outras publicações. Estes dispositivos, que Olivero (1999) chama de aparelho crítico de uma coleção, produzem um intertexto que unifica os diferentes volumes publicados. Mas é preciso pensá-los, também, como dispositivos de configuração e legitimacão dos saberes pedagógicos que a coleção seleciona e compendia em diversos volumes, no intuito de divulgá-los. ${ }^{4}$ É assim que o aparelho crítico da Biblioteca da Educação funciona como dispositivo de territorialização dos volumes publicados no campo dos saberes pedagógicos que a própria coleção produz e configura.

É no bojo de inúmeras iniciativas de reforma do sistema escolar que têm lugar no Brasil, nos anos 1920, que uma nova modalidade de impresso pedagógico se firma no mercado editorial, tornando obsoleto o livro único de Pedagogia, manual em que se dispõem práticas modelares ou em que se compendiam os saberes representados como fundamentos da prática docente. Esta modalidade de impresso tende a ser substituída por coleções especialmente voltadas para a formação docente. Nessas coleções, montam-se redes de impressos como bibliotecas para professores.

O livro único de Pedagogia perde a capacidade de compendiar o conjunto dos saberes representados como necessários ao exercício da prática docente e essas bibliotecas vêm desempenhar esse papel. Nelas, os impressos dirigidos aos professores não fornecem roteiros de lições, nem tampouco descrevem práticas exemplares. Preferem subsidiar a prática docente ao fornecer informações que funcionem como leque de alternativas de ação na sala de aula e como repertório de conhecimentos especializados que lhe sirvam de fundamento.

No campo normativo da Pedagogia que configura essas coleções, os usos do impresso são regulados por normas distintas daquelas que prescrevem a arte de bem ensinar como boa cópia de modelos e a arte de bem aprender como exercício adequado das faculdades da alma. No caso brasileiro, nessas coleções, a Pedagogia da Escola Nova entra em cena, recusando-se a fornecer modelos para serem imitados ou roteiros de lições para serem seguidos. A Pedagogia deixa de fornecer cânones para oferecer fundamentos, subsidiando a prática docente com o repertório de saberes que põe em circulaçao, legitimando-os.

O estudo de coleções pedagógicas publicadas nas décadas de 1920 e 1930, como é o caso da Biblioteca de Educação, não pode prescindir do estudo das estratégias que as produziram e as puseram em circulação, situando-as em um lugar de poder: o das posições que seus organizadores ocuparam como profissionais e políticos encarregados da gestão e da reforma dos sistemas públicos de ensino.

\footnotetext{
${ }^{4}$ Ver Carvalho $(2001 ; 2006)$.
} 
Assim, é preciso pensar essas coleções como produtos de estratégias editoriais e pedagógicas articuladas ao programa de reforma da sociedade pela reforma da escola que mobilizou, nessas décadas, toda uma geração de intelectuais que se fizeram educadores profissionais ao se empenharem na remodelação da instrução pública segundo novas idéias pedagógicas que circulavam internacionalmente ${ }^{5}$. Foi, assim, na posição de gestores dos sistemas públicos de ensino, que esses intelectuais marcaram presença no mercado editorial como autores, tradutores e organizadores de coleções destinadas a professores.

A estratégia editorial que presidiu a publicação da Biblioteca de Educação nas décadas de 1920 e 1930 articula o livro a uma pauta de iniciativas destinadas a promover uma mudança da mentalidade do professor, mudança entendida por seu editor, Lourenço Filho, como condição de possibilidade de reforma da escola. Nessa estratégia, a Biblioteca de Educação é a coleção que compendia os saberes pedagógicos necessários à transformação da mentalidade e da prática do professorado que o reformador, Lourenço Filho, julgava imperativa.

Nela, formar o professor, transformar a sua mentalidade, era levá-lo à compreensão das novas finalidades sociais da escola, que o editor entendia inscritas nos fundamentos da chamada Pedagogia da Escola Nova. Era fazê-lo percorrer o caminho de superação de suas concepções sobre a atividade do aluno, deslocando-as do terreno constituído por uma pedagogia centrada no exercício das faculdades da criança e iniciando-o no conhecimento das então mais recentes descobertas do campo da Psicologia e em uma mais adequada compreensão das conseqüências desse conhecimento para a prática docente.

Assim, organizados como pequenos manuais que condensam as modernas idéias e práticas da educação, os volumes da Coleção se dispõem como peças de um conjunto harmônico destinado a constituir a cultura pedagógica do professorado. Na lógica que preside a organização da Coleção, organiza-se um repertório de saberes autorizados, destinados a fundamentar a prática docente. Saberes selecionados e hierarquizados pela avaliação que o editor faz das disposições, expectativas e competências de seu público leitor e pelos requisitos que identifica necessários à mudança que programa gradativamente promover no espírito do professorado quanto à filosofia do ensino.

É nesse projeto editorial, de claro direcionamento cultural e pedagógico, que se inscreve a publicação de Educação moral e educação econômica. Suas bases e sua aplicação nas escolas, como terceiro volume da coleção. Publicado em 1928, é livro produzido sob encomenda. A sua simples publicação na Biblioteca, como o seu terceiro volume, quando tinham apenas sido publicados nela os livros de Henri Pieron, Psicologia experimental, e de Claparède, $A$ escola e a psicologia experimental, indicia o prestígio de que gozava Dória junto ao organizador da coleção, seu ex-aluno na Escola Normal de São Paulo e antigo amigo, compadre, discípulo e colaborador.

Figurar na Biblioteca de Educação, ao lado de dois pedagogos então internacionalmente ilustres, que protagonizavam o movimento internacional pela Escola

\footnotetext{
${ }^{5}$ A respeito do empenho de Lourenço Filho em promover uma transformação radical da cultura pedagógica do professorado, ver, especialmente, sua correspondência a João Hippolito da Costa, in Carvalho, 2000; 2001; 2002. Sobre a função autoral do organizador da coleção, ver Toledo (2001), Carvalho (2004), Carvalho e Toledo (2003; 2006).
} 
Nova, era sem dúvida uma honra para Sampaio Dória. Mas a escolha do tema reservado para Dória no elenco dos títulos previstos na coleção, assim como as estratégias discursivas de apresentação do autor mobilizadas no prefácio do livro, podem indicar a ambigüidade da situação.

Como dispositivo do que Olivero (1999) chama de aparelho critico, o prefácio do volume dá a ver as estratégias discursivas de enquadramento do livro na coleção, territorializando-o na periferia do movimento de renovação pedagógica que o prefaciador do volume e editor da coleção capitaneava no país. Tais estratégias funcionavam também como dispositivos de abertura de espaço às novas tendências pedagógicas que o pedagogo/editor pretendia difundir, combatendo convicções e teorias pedagógicas como aquelas que Dória vinha difundindo em seus escritos sobre Pedagogia. Ficam evidentes, nesse prefácio, as estratégias textuais que compõem o perfil de Dória e de suas idéias educativas, de modo a reverenciá-las e a, concomitantemente, alocá-las em território devidamente delimitado, de modo a assegurar que não contaminassem as proposições que o prefaciador considerava de maior impacto na renovação do campo pedagógico.

Já o título do volume Educação moral e educação econômica. Suas bases e sua aplicação nas escolas cumpre essa função. O tema era, sem dúvida, relevante no campo da chamada Pedagogia da Escola Nova, cujos difusores europeus, profundamente impactados pela guerra de 1914, propunham-se a transformar os conceitos e as práticas pedagógicas de modo a fazer surgir um novo homem e forjar uma nova era. Mas no cerne desses propósitos renovadores estavam transformações conceituais de grande envergadura, que vinham reconfigurando a Psicologia e a Filosofia e produzindo novas representações sobre a criança e sobre os processos de ensino e aprendizagem. A lógica que preside a organização da Biblioteca contempla tais transformações.

Segundo essa lógica importava, como se viu, conduzir o leitor a percorrer o caminho que o levasse a abandonar velhas concepções sobre a atividade da criança e sobre o exercício de suas faculdades; concepções estas dominantes nos meios pedagógicos brasileiros até então. Eram concepções deste tipo que, por exemplo, fundamentavam as explanações e os preceitos formulados por Dória, em seu primeiro livro, Princípios de pedagogia, publicado em 1914, que estão presentes também em Educação e em Psicologia, publicados, inicialmente, na década de 1920, pela Companhia Gráfico-Editora Monteiro Lobato e republicados depois, respectivamente em 1934 e 1932, na Série Livros Didáticos da Biblioteca Pedagógica Brasileira, dirigida por Fernando de Azevedo para a Companhia Editora Nacional. ${ }^{6}$

A escolha do título do volume de autoria de Dória parece estratégica. Para discorrer sobre o tema, o autor poderia permanecer fiel aos preceitos pedagógicos que professava desde a década de 1910, sem que isso comprometesse o programa pedagógico/editorial da coleção, em que era nuclear a divulgação das transformações conceituais que reconfiguravam a Filosofia e a Psicologia e, com ela, as representações correntes sobre a natureza infantil. Bastava que o trabalho do prefaciador situasse o autor e o tema por ele tratado em uma das tendências da pedagogia renovada, alijando-o do campo teórico em que tais transformações se produziam.

\footnotetext{
${ }^{6}$ Sobre a coleção Atualidades Pedagógicas e a importância dos dispositivos editoriais e autorais que conferem identidade a uma coleção, ver Toledo (2001).
} 
É assim que, ao prefaciar o livro, traçando o perfil do seu autor e fixando balizas para sua leitura, Lourenço Filho põe em relevo o pedagogista social. Para o prefaciador e organizador da coleção, o livro compendia as preleções metodológicas de Dória no campo em que, segundo o juízo do organizador da coleção, maior era a importância e, sobretudo, a atualidade da pedagogia de Dória: seu caráter de pedagogia social. É o que se pode ler a seguir:

Por um caminho inverso ao dos cultores da sociologia positiva que, partindo do estudo histórico das sociedades mais atrasadas, chegam `as instituições livres de hoje, para afirmar que nelas a educação é o pêndulo regulador, Sampaio Dória deduz do 'estado ideal' as normas de sua construção. No caso brasileiro, vê como passo inicial, a necessidade de alfabetização do povo. A soberania popular não pode existir sem ela. A primeira função do estado é pois educar. Elaborando um sistema de idéias originais, quanto às necessidades brasileiras, ele pode assim inscrever-se na corrente idealista alemã, em que Natorp culmina. Subscreveria, em tal autor, a noção de pedagogia como a obra total de elevação do homem ao mais alto grau de perfeição humana. Razão porque a pedagogia é sempre social e, por isso mesmo, nunca um sistema de educação do indivíduo isolado, mas a do homem que vive em comunidade. (Lourenço Filho, 1928, p. 6)

Para um leitor atento e informado, ficam evidentes as estratégias textuais que compõem o perfil de Dória e de suas idéias educativas, que Lourenço Filho traça no prefácio, de modo a adequá-lo, não somente à coleção mas, principalmente, às novas tendências pedagógicas que identificava no movimento internacional pela Escola Nova. É assim que, com um visível esforço de enquadramento da pedagogia professada pelo antigo mestre no projeto editorial que presidia a organização da Biblioteca da Educação, Lourenço Filho territorializa a produção de Dória no campo de uma das duas tendências que considerava dominantes nesse movimento: 0 da reação de crítica social desencadeada pela guerra de 1914.

Um breve percurso pelas páginas de Introdução ao estudo da escola nova, de autoria de Lourenço Filho, ilumina a questão. Publicado como volume da Coleção, o livro é a peça central desta: é o espaço em que os diversos volumes que a integram se articulam e ganham inteligibilidade como dispositivos de uma estratégia editorial cujo objetivo é a formação de uma nova cultura pedagógica do professorado, condição de possibilidade de institucionalização de uma nova escola. Nos dispositivos que compõem o aparelho crítico do volume, como prefácio e notas de rodapé, as explanações abrem-se em leque para os assuntos tratados nos outros volumes da coleção, prescrevendo modos de lê-los e de utilizar o lido.

Inscrito na lógica editorial que preside a produção da coleção, Introdução ao estudo da escola nova pode ser lido como dispositivo de luta pela hegemonia doutrinária no campo da Pedagogia, no conturbado cenário político dos anos iniciais da década de 1930. ${ }^{7}$ Tratava-se de pôr em cena, seletivamente, em linguagem acessível e de modo sistematizado, os novos sistemas de educação renovada, exibindo-lhes os fundamentos e

\footnotetext{
${ }^{7}$ Ver a respeito Carvalho (2002).
} 
fixando-Ihes o sentido, de modo a demarcar sua diferença relativamente à pedagogia tradicional, mas também a torná-los palatáveis a seus mais ferrenhos críticos.

No prefácio à primeira edição, Lourenço Filho aborda a origem, o caráter e o objetivo da publicação: livro de iniciação no assunto, um "modesto livrinho" que deveria permitir uma "visão geral e completa do problema", de modo a preencher uma lacuna na bibliografia disponível, que se estruturava como espécie de "topografia geral, em escala reduzida, situando apenas os acidentes capitais" do movimento internacional pela Escola Nova (1930, p. 12). Obra de síntese e de introdução ao assunto, o livro, como, de resto, frisava, os demais que, com ele, compunham a Biblioteca de Educação, propunha-se a promover a "formação de uma nova mentalidade dos que educam, pais e mestres":

Formar essa nova mentalidade, liberta e esclarecida, como esclarecer mais e mais a opinião pública, acerca das novas idéias da educação é tarefa instante, que se impõe a todos os que crêem no Brasil... Faltam-nos, desgraçadamente, nucleos superiores de elaboração de um pensamento nacional que busquem, lá fora, o método de trabalho e o incentivo das novas idéias, não há dúvida, mas procurem decifrar aqui, dentro de nós mesmos, as nossas próprias incógnitas. [...] Até lograrmos esses aparelhos de cultura, esses focos de consciente brasilidade, será preciso insistir, por todos os meios, pela propaganda honesta, pela evidência do incentivo que nos dão outros povos, em que há novas formas de civilização e de cultura. (1930, p. 12)

Objetivos de sistematização e síntese explicitados no prefácio estruturam Introdução ao estudo da escola nova organizando-o em cinco capítulos, apresentados como lições, cada uma delas didaticamente seguidas de um resumo e conclusão. Três desses capítulos apresentam os traços gerais dos sistemas de educação renovada. A Lição $V$ trata de Questões gerais de aplicação. A Lição I tem estrategicamente por título uma pergunta: Que se deve entender por escola nova?

É essa primeira lição do livro que fornece os protocolos de leitura das matérias tratadas nas lições subsequentes. Nela, a pergunta que dá nome à lição - Que se deve entender por escola nova? - é dispositivo de estruturação textual cuja função principal é fazer tábula rasa das informações e das concepções pedagógicas do leitor, de modo a melhor estabelecer as coordenadas principais para o seu entendimento. No seu funcionamento, a pergunta remete essas informações e concepções para o território de uma pretensa confusão em torno do assunto. A partir desse patamar, a pergunta opera de modo a produzir discernimento em torno do que deve e do que não deve ser compreendido "como novo em nossos dias". (Lourenço Filho, s/d, p. 2).

A resposta dada é gradativamente construída de modo a fazer emergir, da confusão imperante, o novo. Vai encontrá-lo, primeiro, no movimento de revisão social dos fins da educação imposto pela guerra e nos avanços da ciência. A guerra dera

maior relevo ao caso social da obra educativa intencional dos governos, e das instituições devotadas a uma humanidade melhor, gerando um movimento de crítica social em pról de um reajustamento de fins da educação: Mal refeita ainda do cataclisma que foi a guerra mundial, a humanidade se volta para as gerações de amanhã, na ânsia de um destino melhor, incansavelmente buscado. Fatigado de emendar e corrigir, o homem feito volve as vistas para a criança, para a linfa pura, ou menos 
contaminada das fontes. Em todos os países, políticos esclarecidos pregam a educação do povo, como condição do equilíbrio social, mais duradouro e perfeito. Filósofos e pensadores põem nela o ideal da união futura de todas as raças, de todas as nações. (Lourenço Filho, s/d, p. 2)

A conflagração mundial viera "impor aos educadores a revisão dos fins tentados pela escola pública". Em sintonia com essa "reação de crítica social" desencadeada pela guerra, "a ciência da educação ou a sociologia educacional ensinava que a educação é socialização da criança" (Lourenço Filho, s/d, p. 5).

Mas essa "reação de crítica social" não é, no entender de Lourenço Filho, a tendência principal do movimento internacional pela escola que importava divulgar e dar a conhecer. Isso porque, como também apregoa a primeira lição do livro, ela havia sido precedida por uma "reação de crítica psicológica, bem caracterizada, e que procurava demonstrar a inanidade dos meios em ação nas escolas, fossem quais fossem os fins por elas visados" (Lourenço Filho, s/d, p. 3).

O "progresso das Ciências Biológicas e, em particular o da Psicologia", no último quartel do século 19, era, no entender do autor do livro e editor da coleção, o principal responsável pelo "formidável movimento renovador" (Lourenço Filho, s/d, p. 4-5). É, assim, no domínio da tendência de crítica psicológica relativa aos meios que a Coleção e, particularmente, Introdução ao estudo da escola nova vão investir de modo mais abrangente e incisivo no combate aos equívocos sobre o sentido da nova educação. Embora a referida tendência de crítica psicológica não incidisse diretamente sobre a questão das finalidades da educação, ela tinha enorme peso em sua determinação, já que "a ciência fulmina de ridículo ao reformador que se proponha idéias fantásticas" (Lourenço Filho, s/d, p. 5).

Desconsiderar, portanto, os inegáveis avanços da ciência, em particular da Psicologia, seria condenar ao fracasso qualquer ação educativa. Mais do que isso, difundir tais avanços era, como se viu, um dos principais objetivos da Biblioteca da Educação, que pretendia fazer o leitor/professor trilhar o caminho de superação de suas concepções sobre a atividade do aluno, deslocando-as do terreno constituído por uma pedagogia centrada no exercício das faculdades da criança e iniciando-o no conhecimento das então mais recentes descobertas do campo da Psicologia. Para isso, importava demarcar a distância entre os velhos processos do ensino intuitivo e os da nova escola ativa, concebida nos marcos da ciência produzida como reação de crítica psicológica às velhas idéias.

Trata-se de evidenciar a diferença entre a concepção de atividade da criança que vinha norteando aqueles velhos processos, como era o caso das proposições até então defendidas pelo pedagogo Sampaio Dória, e a nova concepção acerca da atividade infantil, expressão das modernas tendências filosóficas e fundada nos avanços da Psicologia. Por isso, não é como expressão da chamada tendência de crítica psicológica que o editor e prefaciador Lourenço Filho enquadra Educação moral e educação econômica, mas sim como volume que deveria ser lido à luz da tendência de "crítica social em pról de um reajustamento dos fins da educação" do movimento de renovação educacional (Lourenço Filho, s/d, p. 2).

No prefácio de Educação moral e educação econômica, Lourenço Filho destaca a importância histórica das concepções pedagógicas de seu antigo professor na Escola 
Normal, bem como ressalta o caráter social de sua pedagogia. Segundo o seu testemunho de aluno e colaborador, a Pedagogia não podia, para Dória, ser considerada "um sistema de educação do indivíduo isolado, mas a do homem em comunidade" (Lourenço Filho, 1928, p. 6).

Tal concepção pedagógica faria, no entender do prefaciador, com que Dória orientasse o "ensino de pedagogia para uma finalidade de política nacional de cultura". Nos cursos que dera na Escola Normal, por dez anos, suas lições "chegavam sempre às normas de uma teoria universal da educação, sem perder nunca o endereço social de nosso caso, do caso brasileiro" (Lourenço Filho, 1928, p. 7). Essa operação punha, sem dúvida, em evidência uma vertente da pedagogia de Dória, manifesta em inúmeras publicações. Mas ela minimizava a importância de outras dimensões desta pedagogia, certamente não compatíveis com o projeto de renovação do campo pedagógico posto em movimento pela publicação da Biblioteca da Educação.

O título do volume reservado para Dória era, sem dúvida, do interesse deste, se levarmos em conta a extensa produção bibliográfica do já então especialista em Direito Constitucional e catedrático da Faculdade de Direito de São Paulo e do antigo militante da Liga Nacionalista de São Paulo, que havia abraçado a bandeira da cidadania e erigido a alfabetização dos paulistas em sua meta central como reformador da instrução pública, em 1920. Já em um dos seus primeiros livros publicados, Ensaios, o interesse pela formação moral e pela educação cívica é central. Mais vinculados à sua militância política, como membro da Liga Nacionalista de São Paulo e como reformador da Instrução Pública em 1920, outros trabalhos são testemunhos desse interesse. Alguns deles, como Instrução pelo estado (1922), A questão social (1922), e O espírito das democracias (1924), e Questões de ensino (1921) são intervenções no debate em curso sobre questões de política educacional, envolvendo temas jurídicos, filosóficos, sociais e econômicos.

O espírito das democracias é obra de militância que reúne conferências de propaganda cívico-doutrinária, parte delas proferida como militante da Liga Nacionalista de São Paulo. Questão social e Instrução pelo Estado são obras de perfil mais acadêmico que transitam nesse mesmo território que Lourenço Filho classifica como o da Pedagogia Social. A primeira obra pretende fixar os princípios que deveriam inspirar a legislação social no Brasil, entendendo ser "preciso reformar, profundamente, a organização econômica do mundo", pois onde quer que "o trabalhador viva sem amparo face ao capital a justiça não estará segura de sua eficiência" (Dória, 1922, p. 378). Instrução pelo Estado é texto produzido como resposta à questão "Coaduna-se a instrução primária obrigatória com os princípios que regem a ação social do Estado?” Neste livro, Sampaio Dória articula a discussão dessa questão ao esclarecimento de algumas das medidas da Reforma de 1920.

Questões de ensino reúne cartas, palestras, documentos, conferências e artigos publicados em jornais, relacionados à Reforma de 1920. Nele, o autor traz informações e argumentos que, no seu entender, contribuíam para uma melhor compreensão dos princípios que nortearam sua ação como reformador; de sua participação no processo de concepção, elaboração e implementação da reforma; e das razões que o levaram a pedir exoneração do cargo de diretor geral da Instrução Pública, antes mesmo de sua regulamentação. Com a reunião deles em um único livro, pretendeu defender os 
princípios que nortearam a versão original do projeto de Reforma que elaborou, criticando as deturpações que sofreu e respondendo às críticas que recebeu durante o seu processo de tramitação.

Como pode indicar essa extensa bibliografia pedagógica, a escolha de Dória para produzir, para a coleção, o volume Educação moral e econômica era até certo ponto acertada. Mas reservar para Dória o tratamento desse tema na Biblioteca era negar espaço de circulação para as proposições conceituais e metodológicas do autor em campo muito freqüentado por ele: o do que ele entendia como Pedagogia científica e Psicologia.

Ao fixar o perfil do autor do volume como pedagogista social, relativizando a importância de outras incursões de Dória no campo pedagógico, o prefaciador era seletivo. Mais do que isso, na territorialização que a coleção promove, fragmentando os assuntos por volume e destinando cada um deles a um autor escolhido, era um dos territórios em que o pedagogo Dória costumava se mover que lhe era subtraído.

A Psicologia Experimental, peça inamovível desse território e tema tão recorrente na produção pedagógica de Dória, era assunto destinado a outros autores, mais identificáveis com as proposições e conceitos que Lourenço Filho acreditava nucleares no movimento internacional pela Escola Nova. Não a quaisquer autores, mas a duas das principais autoridades no assunto, internacionalmente reconhecidas.

É, dessa forma, conivente com as escolhas do editor ao aceitar o convite que lhe foi feito para escrever o volume, que Dória é expelido de um território antes bastante freqüentado por ele: o da Pedagogia como ciência e de seus fundamentos na Psicologia. Era nesse território, onde se propunha a colaborar na obra de constituição de uma Pedagogia científica, que Dória ia freqüentemente colher os fundamentos para suas proposições sobre educação moral, tema do volume.

Assim, um olhar atento ao modo como Lourenço Filho faz, no prefácio de Educação moral e educação econômica, a apologia do seu antigo professor, permite identificar um conjunto de estratégias discursivas que promovem a territorialização da Pedagogia por este professada no novo campo dos saberes pedagógicos que a publicação da Biblioteca visava produzir. Cristalizada nas palavras autorizadas com que Lourenço Filho, no auge de seu prestígio político e técnico, prefaciava o volume, a imagem de seu autor como pedagogo social confina Dória em um lugar pequeno demais para acomodá-lo. Mais do que isso, o prefácio não fazia justiça, minimizando a importância histórica de um dos temas de predileção do pedagogo Sampaio Dória: o estabelecimento da Pedagogia como ciência.

As concepções pedagógicas de Dória foram difundidas por significativa produção bibliográfica, irradiando-se para públicos muito mais amplos que os das salas de aula e para além do período em que foi o mestre da Escola Normal Secundária da capital paulista. Entre os livros que publicou, destaca-se Princípios de pedagogia, publicado em 1914, que põe em circulação a tese que apresentou no concurso de cátedra que prestou nessa Escola. Nele estão expostas as concepções sobre educação, Pedagogia, Psicologia da criança e ciência que muito certamente balizaram os ensinamentos que ministrou nessa escola ao longo de mais de dez anos.

Aquilatar a importância de Princípios de pedagogia na minguada produção pedagógica brasileira das primeiras décadas do século 20 não é tarefa fácil. Ela supõe 
que nos desloquemos para o território conceitual movediço em que estava em curso, internacionalmente, desde o final do século anterior, a constituição do que era entendido como ciência da educação. O livro de Dória move-se nesse território, dialogando com autores de distinta extração disciplinar, orientação teórica muitas vezes incompatível e de importância muito variável, cujo denominador comum era a larga circulação que tiveram no período.

Entre eles, destacam-se alguns, muito conhecidos ainda hoje, como Rousseau, Haeckel, Comte, Spencer, Emerson, Binet, Claparède, Buisson, Compayré, Wundt, William James e Stuart Mill; mas também, outros, hoje desconhecidos de públicos não especializados, como Grasset, Le Bon, Flournoy, Berillon, Bezold, Bernnhein, Mosso, etc. É dialogando com esses autores que Dória se lança ao empreendimento de fixar os princípios de Pedagogia capazes de nortear as políticas educacionais e as práticas de sala de aula. Mas será, sobretudo, a interlocução com Spencer, de quem empresta a convicção de que o "ideal educativo do homem é a preparação para a vida completa" (Dória, 1914, p. 6), que imprimirá ao texto sua fisionomia.

Conhecer a criança, mais precisamente, conhecer "a alma infantil com as leis da sua evolução" (Dória, 1915, p. 11) era, para o pedagogo, a pedra de toque do sucesso da educação infantil. Por isso, o livro se propõe a expor "as linhas gerais que dominam toda a vasta extensão da ciência da infância, talhando as deduções primeiras da pedagogia experimental" (Dória, 1915, p. 13). É somente depois dessa longa incursão pelos meandros das leis que regem o desenvolvimento infantil que Dória, não sem antes referir os estudos de Binet sobre os tipos mentais, sintetiza sua posição sobre o estatuto da ciência da educação, afirmando não ser possível colocar em dúvida que "ela se forma de preceitos da Psicologia infantil, da higiene e da sociologia” (Dória, 1915, p. 51).

Tratava-se, por isso, para ele, de uma ciência formal que, como o Direito, não teria conteúdo próprio, do que decorreria a sua dificuldade teórica e prática e a necessidade de aliar o psicólogo, o médico escolar e o pedagogo na ação educativa. Essa aliança deveria chegar às salas de aula, a partir de complexas medições realizadas nos laboratórios de Psicologia e antropologia e da institucionalização de fichas médico-pedagógicas com registros do adiantamento dos alunos. O uso dessas fichas permitiria evitar um empirismo obscuro, entendido como "limbo preparatório para a claridade salvadora" (Dória, 1915, p. 52-53) que substituiria a indistinção dos alunos em aula pela fixação dos tipos escolares.

A adoção de procedimentos desse tipo era fundamental, mas insuficiente. A Pedagogia científica exigia o concurso de estudiosos que lhe resolvessem os incontáveis problemas, muitos deles apenas esboçados, outros ainda a formular. Da "solução científica de todos" dependeria "a ortopedia mental e moral das gerações atuais e futuras" (Dória, 1915, p. 52).

Segundo o autor, muitos educadores vinham apregoando o advento de uma nova pedagogia, sem ligações com o passado. Entre eles Binet, que "lança o pregão de morte à antiga pedagogia, [...] resultado de idéias preconcebidas", toda feita de afirmações gratuitas, que "confunde demonstrações rigorosas com citações literárias" (Dória, 1915, p. 57-58).

Outra não seria, para o autor, a posição de Buisson, para quem a ciência da educação estaria edificada em "concepções de puras filosofias", apresentando-se como "uma ciência de literatura e sonho, uma ciência empírica, assaz incerta em seu propósito 
e seus princípios, algumas vezes incoerente em seus processos e meios de ação, quando resultado exclusivo da prática dos profissionais" (Dória, 1915, p. 57-58).

Contra essa situação é que surgia uma "pedagogia nova, toda feita de observações e experiências na acepção científica da palavra, construída sobre as ruínas da antiga pedagogia" (Dória, 1915, p. 57-58). São dados antropométricos, medidas fisiológicas, indicações cardiográficas, e registros cefalométricos das crianças e toda sorte de medidas a que elas deveriam se submeter nos laboratórios de psicologia e antropologia que vão configurando essa nova pedagogia. Mas são também os preceitos de higiene infantil e escolar; os conhecimentos da Psicologia sobre os tipos infantis, sobre as leis da fadiga e da sugestibilidade; as indicações práticas para a ortopedia mental e moral dos anormais etc. Tudo isso, conclui Dória, concorre

para a boa organização escolar, desde o estabelecimentos das fichas medico-pedagógicas até as instalações em prédios higiênicos e apropriados, desde os programas até o regimem disciplinar, os horários, os exames, os recreios, as férias, a freqüência obrigatória. (Dória, 1915, p. $57-58)$

É pertinente registrar que as teses difundidas por Dória em Princípios de pedagogia têm estreita relação e semelhança com as que, defendidas por Oscar Thompson, presidiram a instalação, em 1914, mesmo ano em que o livro foi publicado, do Laboratório de Pedagogia Experimental, no Gabinete de Psicologia e Antropologia Pedagógica, anexo à Escola Normal. ${ }^{8}$ Thompson era, então, diretor da Escola Normal Secundária da capital paulista. Nas justificativas que apresentou para a instalação do Laboratório estão presentes as mesmas tópicas e os mesmos propósitos de fundação de uma ciência da educação alicerçada em medições e experiências laboratoriais com crianças ${ }^{9}$.

Mas Princípios de pedagogia é, sem dúvida, menos marcado pelo afã de identificar marcas e sinais de anormalidade nas crianças, de modo a delimitar o campo da normalidade para nele radicar a ação educativa em total sintonia com a natureza. Esses temas estão presentes na pedagogia de Sampaio Dória mas, diferentemente das formulações de Thompson, essa pedagogia se constrói guardando alguma distância das práticas de laboratório e demarcando, a priori, as fronteiras entre o ato clínico e o ato educativo; entre a escola, a prisão, o asilo e o hospício. Princípios de pedagogia não se deixa confinar no espaço do laboratório e de suas minudentes e intrincadas medições e classificações. As múltiplas mensurações e classificações neles produzidas têm um lugar importante na pedagogia de Dória, especialmente como recurso apto a fixar os tipos escolares, para, com eles, identificar diferenças na indistinção bruta com que os alunos se apresentam em sala de aula, classificando-os e superando, desse modo, o desacerto de práticas de ensino norteadas por um empirismo obscuro.

As práticas laboratoriais permitiam lidar, segundo Dória, com um dos fatores determinantes do desenvolvimento da criança: o coeficiente individual. Mas, justamente por isso, sua importância tinha uma contrapartida: tais práticas tinham o seu lugar delimitado pela relação de complementaridade que o coeficiente individual, seu campo de

${ }^{8}$ Sobre as teses defendidas por Thompson na ocasião e sobre o Laboratório, ver Carvalho (2006) e Tavares (1996).

${ }^{9}$ Ver Thompson (1914). 
ação, mantinha com o fator determinante principal, este social, a lei de recapitulação abreviada, de que o primeiro fixava apenas variações ou exceções bem delimitadas. Era dessa lei maior, que determinava as diretrizes do desenvolvimento da espécie e, por paralelismo, do indivíduo, e não das infindáveis medições laboratoriais, que Dória iria extrair o fundamento do método de ensino que prescrevia, como garantia do desenvolvimento da criança e de sua educação: o método intuitivo. A importância e a força desse método derivava de sua total adequação a essa lei maior, na medida em que nele e com ele a criança podia aprender, trilhando os mesmos passos dados pela humanidade no processo de civilização.

É assim que, nas páginas de Princípios de pedagogia, o discurso do pedagogo se desloca do universo sombrio e carrancudo da ortopedia das práticas de medição do laboratório e do embate travado, dentro e fora dos seus muros, contra e a favor das determinações do desenvolvimento infantil, para o mundo amável e risonho da vida escolar que uma aposta otimista no desenvolvimento natural da criança fazia entrever. $A$ aposta vinha referenciada em notáveis pedagogos, como Pestalozzi, para quem, dizia Dória, nada deveria intermediar a relação entre a criança e a natureza. Nas representações que o livro passa a encenar, a criança aparece como o principal agente de sua evolução. Exorbitaria o mestre que de algum modo cerceasse a sua "livre atividade" (Dória, 1914, p. 68) ou que Ihe impusesse sobrecarga excessiva. Importava favorecer o exercício da atividade do aluno.

$\mathrm{Na}$ intrincada e complexa inter-relação entre conhecer as leis da natureza infantil para melhor favorecê-las e agir ortopedicamente para assegurar que o processo educativo cumprisse uma finalidade estipulada, a ação educativa, tal como a prescreve Princípios de pedagogia, é prática marcada por instável e difícil equilíbrio. Para garantir esse equilíbrio, a pedagogia de Dória apostava na colaboração da natureza. O método de intuição analítica era, no seu entender, totalmente conforme a psicologia evolutiva da criança, compreendida similarmente a ele, como passagem da visão sincrética para a sintética, mediada pelos processos analíticos.

Essa aposta nas possibilidades educativas de um método de ensino conforme à natureza fazia entrever imagens idílicas de uma escola sem castigos. Em harmonia com a natureza evolutiva da infância, o método intuitivo e um programa de ensino com ele compatível dispensariam castigos e emulações. Isso porque, desde que o ensino se fizesse com qualidade, quantidade, ocasião e modos propícios, o prazer de aprender regeria a vida escolar das crianças, impelindo-as ao estudo:

Das próprias entranhas do assunto tratado intuitivamente, jorra a sedução invisível, que atrai, retém e enfeitiça os educandos. A escola se lhes afigura em prolongamento suave da casa materna. Sem cair no exagero do mero divertimento, o estudo aí se reveste de um agrado semelhante ao dos jogos nos recreios. O menino corre para as aulas, como em busca de um lugar encantado. Tudo aí o prende, o encanta, o seduz. (Dória, 1914, p. 109-110)

Aqui, a distância entre a escola e o laboratório ficava bem demarcada. Mas essa não era ainda a realidade das escolas, não apenas porque seus métodos de ensino estavam ainda em desacordo com a natureza da criança. Os castigos persistiam e deviam 
permanecer nas salas de aula em que a homogeneidade das classes não fosse uma realidade. Assim, evidenciando os limites das imagens idílicas de uma escola sem castigos, sanções disciplinares ainda eram requisitadas por Dória como partes constitutivas da rotina escolar. Não seria conveniente suprimi-las, dada a necessidade de corrigir a conduta dos anômalos morais que a freqüentavam.

No caso destes, a educação não podia contar com a natureza, ao contrário, fazia-se correção do desvio e da anormalidade; fazia-se contra a natureza do educando. Uma escola sem castigos era, por isso, ainda uma utopia. Mas fazia-se anunciar nas expectativas de identificação, individuação e classificação dos alunos que alimentavam a aposta nas experiências de laboratório, mas também na multiplicidade dos novos tests, aplicáveis em situação de sala de aula, que a nova psicologia tornava disponíveis. Seu atrelamento a esse tipo de aposta evidencia que o espaço da sala de aula é compreendido por Dória como extensão do laboratório.

Não era, entretanto, apenas essa aposta que nutria as expectativas que Dória depositava nas experiências de laboratório e nos tests. Tais práticas, principalmente os tests mentais, podiam prestar inestimável auxílio à verificação da "valia prática de um processo didático" (Dória, 1914, p. 106). Defender procedimentos de aferição da valia prática de um método era questão de coerência, para quem apostava no advento próximo de uma Pedagogia científica. Essa pedagogia não era ainda uma realidade, mas isso não era, para Dória, motivo de desesperança:

Que vem a ser a pedagogia, a despeito dos progressos atuais senão um conjunto de preceitos em grande parte empíricos, baseados em uma psicologia só em parte experimental? Não há, contudo, por que desesperar. Ela terá o seu dia de glórias científicas. É continuarem sem desfalecimentos estes estudos experimentais, em que se empenha o mundo culto. (Dória, 1914, p. 97-98)

Assim, seja pela necessidade de assentar a Pedagogia sobre bases científicas, seja pelos limites das experiências de laboratório, a sala de aula se apresenta como um prolongamento deste, pondo a nú outra face do quotidiano das crianças nas escolas harmoniosamente montadas em sintonia com a natureza evolutiva da infância. É assim que, em consonância com outras inúmeras iniciativas que, desde as últimas décadas do século 19, configuravam e legitimavam internacionalmente a Pedagogia como ciência, Princípios de pedagogia faz a sua parte: o olhar que lança sobre a criança e sobre a escola submete as práticas de sala de aula e os saberes que as norteiam às provas e contraprovas da experiência que quer cientificamente controladas. Mas estamos aqui muito distantes da Pedagogia da Escola Nova que o editor da Biblioteca de Educação, Lourenço Filho, programava difundir e promover, por meio do impresso, uma mudança de mentalidade do professorado.

\section{Referências}

CARVALHO, Marta Maria Chagas de. A caixa de utensílios, o tratado e a biblioteca: pedagogia e práticas de leitura de professores. In: VIDAL, Diana Gonçalves; HILSDORF, Maria Lucia. (org.). Tópicos de história da educação. São Paulo: Edusp, 2001, p. 137-168. 
CARVALHO, Marta Maria Chagas de. Pedagogia da escola nova, produção da natureza infantil e controle doutrinário da escola. In: FREITAS, Marcos Cezar; KHULMANN, Moyses (org.). Os intelectuais na história da infância. São Paulo: Cortez, 2002, p. 373408.

CARVALHO, Marta Maria Chagas de. A escola nova no Brasil: uma perspectiva de estudo. In: Educação em Questão, Natal, v. 21, n. 7, 2004, p. 90-98.

CARVALHO, Marta Maria Chagas de. Livros e revistas para professores: configuração material do impresso e circulação internacional de modelos pedagógicos. In: Pintassilgo, Joaquim; Freitas Marcos Cezar; Mogarro, Maria João; Carvalho, Marta Maria Chagas de. (orgs.). História da escola em Portugal e no Brasil: circulação e apropriação de modelos culturais. Lisboa: Edições Colibri/ Centro de Investigação em Educação da Faculdade de Ciências da Universidade Lisboa, 2006a, p. 141-175.

CARVALHO, Marta Maria Chagas de. Quando a historia da educacão é a história da disciplina e da higienizacão das pessoas. In: FREITAS, M. C. (org.). História social da Infância no Brasil. São Paulo: Cortez, 2006b, p. 291-310.

CARVALHO, Marta Maria Chagas de; TOLEDO, Maria Rita de Almeida. A coleção como estratégia editorial de difusão de modelos pedagógicos: o caso da Biblioteca de Educação, organizada por Lourenço Filho. CONGRESSO BRASILEIRO DE HISTÓRIA DA EDUCAÇÃ̃O, 3, Curitiba. Anais ... Curitiba: SBHE, 2003.

CARVALHO, Marta Maria Chagas de; TOLEDO, Maria Rita de Almeida. A Biblioteca da Educação de Lourenço Filho: uma coleção a serviço de um projeto de inovação pedagógica. Quaestio. Sorocaba: Uniso, 2006, v. 8, p. 47-63.

CARVALHO, Marta Maria Chagas de; TOLEDO, Maria Rita de Almeida. Os sentidos da forma: análise material das coleções de Lourenço Filho e Fernando de Azevedo. In: TABORDA, Marcos. Cinco estudos em história e historiografia da educação. Belo Horizonte: Autêntica, 2007, p. 89-110.

CHARTIER, Roger. El mundo como representación: estudios sobre historia cultural. Barcelona: Gedisa, 1996.

CHARTIER, Roger. A ordem dos livros: leitores, autores e bibliotecas na Europa entre os séculos 14 e 18. Brasília: UNB, 1994.

CHARTIER, Roger. Pluma de ganso, libro de letras, ojo viajero. México: Universidad Iberoamericana, 1997.

DÓRIA, Antonio de Sampaio. Princípios de pedagogia. São Paulo: Pocai-Weiss \& C., 1914.

DÓRIA, Antonio de Sampaio. Ensaios. São Paulo: Pocai-Weiss \& C., 1915.

DÓRIA, Antonio de Sampaio. Instrução pelo estado. São Paulo: Off. Graph. Monteiro Lobato \& Co., 1922.

DÓRIA, Antonio de Sampaio. A questão social. São Paulo: Off. Graph. Monteiro Lobato \& C., 1922.

DÓRIA, Antonio de Sampaio. Questões de ensino. São Paulo: Off. Graph. Monteiro Lobato \& Co., 1923.

DÓRIA, Antonio de Sampaio. O espírito das democracias. São Paulo: Companhia Graphico-Editora Monteiro Lobato, 1924. 
DÓRIA, Antonio de Sampaio. Psychologia. São Paulo: Companhia Editora Nacional, 1932.

DÓRIA, Antonio de Sampaio. Educação. São Paulo: Companhia Editora Nacional, 1933.

DÓRIA, Antonio de Sampaio. Educação moral e educação econômica: suas bases, sua aplicação nas escolas. São Paulo, Companhia Melhoramentos de São Paulo, s/d.

LOURENÇO FILHO, Manoel Bergstrom. Introdução ao estudo da escola nova. São Paulo: Companhia Melhoramentos de S.Paulo, s/d.

MONARCHA, Carlos (org.). Lourenço Filho outros aspectos, mesma obra. Marília: Unesp/ Mercado das Letras, 1997, p. 27-59.

OLIVERO, Isabelle. L'invention de la collection. Paris: Éditions de L'Imec/Éditions de la Maison des Sciences de L' Homme, 1999.

TAVARES, Fausto. A ordem e a medida: escola e psicologia em São Paulo (1890 a 1930). Mimeo. São Paulo: Faculdade de Educação/USP, 1996.

THOMPSON, Oscar. O futuro da pedagogia é científico. In: O laboratório de pedagogia experimental. São Paulo: Tip. Siqueira, Nagel \& Comp., 1914, p. 17-18.

TOLEDO, Maria Rita de Almeida. Coleção atualidades pedagógicas: do projeto político ao projeto editorial (1931-1981). São Paulo: PUCSP, 2001. 295f. Tese (doutorado em Educação). Pontifícia Universidade Católica de São Paulo.

MARTA MARIA CHAGAS DE CARVALHO é doutora em História e Filosofia da Educação pela Universidade de São Paulo. É pesquisadora do Conselho Nacional de Desenvolvimento Científico e Tecnológico (CNPq), com bolsa de produtividade de pesquisa. É professora aposentada do Departamento de Filosofia e Ciências da Educação da Faculdade de Educação da Universidade de São Paulo e orientadora credenciada no Programa de Pós-Graduação em Educação da mesma Faculdade. Está vinculada ao curso de Pós Graduação em História da Universidade Federal de São Paulo - Unifesp - com bolsa de professor visitante senior da Capes.

Endereço: Avenida Pedroso de Morais, 70/72 - 05420-000 - São Paulo - SP - Brasil. E-mail: mchagas.carvalho@gmail.com.

Recebido em 13 de junho de 2012.

Aceito em 21 de setembro de 2012. 